\title{
THE IMPACTS OF DIESEL-PASSENGER-CAR INCENTIVISATION ON EMISSIONS IN IRELAND: HISTORIC ANALYSIS AND POLICY ASSESSMENT FRAMEWORK
}

\author{
MD. SANIUL ALAM ${ }^{1,2}$, PAUL DUFFY ${ }^{2}$, BERNARD HYDE ${ }^{2} \&$ AONGHUS MCNABOLA $^{1}$ \\ ${ }^{1}$ Trinity College, Dublin, Ireland \\ ${ }^{2}$ Environmental Protection Agency, Monaghan, Ireland
}

\begin{abstract}
An assessment was conducted on the air pollution impact of incentivisation of diesel passenger cars to curb carbon emissions in Ireland. Road transport emission inventory data was obtained from the national COPERT5 model for the years 1990-2016. The underlying variables that represent the current carbon-based taxation scheme and the economy were included in a regression analysis with fleet, fuel and engine size data. This data was used to develop a "what-if" scenario which predicted the result of not incentivising diesel cars in 2008, on road transport emissions up to 2016. The mileage of these segregated fleets was also adjusted with income elasticities. The results show that the difference would be approximately a 5.4\% increase of $\mathrm{CO}_{2}$ and $6.4 \%$ for $\mathrm{PM}_{2.5}$ in 2016 without the implementation of the 2008 incentives. $\mathrm{NH}_{3}, \mathrm{CO}$, NMVOC and $\mathrm{CH}_{4}$ would also have been increased by $50.9 \%$ to $61.9 \%$. The nitrogen-based emissions, however, would have reduced by $22.8 \%$ for $\mathrm{NO}_{x}$ and $19.9 \%$ for $\mathrm{N}_{2} \mathrm{O}$. The primary reason for the increase of nitrogen-based emissions was a shift in vehicle purchases to smaller engine diesel passenger cars from both petrol and larger engine diesel cars. The $\mathrm{CO}_{2}$ emission contribution of the smaller diesel passenger car fleet is lower in comparison to the most other fleet technologies. Thus, a change in fleet size in this technology will likely to have the most impact on the emission scenario. Using this knowledge of a fleet shift, a framework tool can be developed to control the future fleet composition. The results of this paper highlight that the incentivisation of one source of air pollution over another is a complex matter with varied results. However, it has been shown that this can be optimised to produce the minimum impact from both climate change and air pollution perspectives, where both are considered in detail.
\end{abstract}

Keywords: air pollution, transport, $\mathrm{CO}_{2}$, emissions modelling, regression.

\section{INTRODUCTION}

Incentivisation of new diesel vehicle purchases has been in place in Europe over the past 10 years, as a means of reducing the $\mathrm{CO}_{2}$ emissions of road transport [1]. However, the success of these government incentives has also resulted in well documented increases in PM and $\mathrm{NO}_{\mathrm{x}}$ emissions [2]. In Ireland, this incentive was introduced in 2008 [3] to curb carbon emissions from passenger cars (PC) that are the largest category of the fleet causing the highest mileage share (77.3\%) [4]. This incentivisation was achieved through changes to the Motor Tax (MT) and Vehicle Registration Tax (VRT) for new vehicles. Previous research reported the impact of harmful $\mathrm{NO}_{\mathrm{x}}$ emission due to this policy reform [3]. In light of the historic analysis in this paper, an adjustment in the taxation is investigated to find a balance in the fleet composition which restricts the fluctuations in the level of growth of different types of emissions, moving towards an optimum fleet emission mix from both air pollution and climate change perspectives. In addition, the impact of not implementing this diesel incentivisation policy was also predicted. 


\section{METHODOLOGY}

The major source of data in this research was collected from the emission inventory of the Environmental Protection Agency (EPA) from 1990 to 2016 [4]. The disaggregated fleet and mileage data by emission standard, fuel type, and engine size for PCs were collected using COPERT 5 software. The estimated emissions for gasoline and diesel PCs (mileage for other PC categories $<0.09 \%$, [4]) were also obtained, and a comparison was made against the emissions modelled under a "what if" scenario. To construct the "what if" scenario, the fleet and mileage data were reconstructed to represent what would have happened without the introduction of the diesel incentive. The fleet size and the total mileage remained the same based on an assumption that the economic growth would be unhampered if total mileage remained the same. The steps in the analysis were presented in Fig. 1.

Eleven macroeconomic, household level expenditure and tax-related indicators were assessed, and the selected indicators were applied to model the "what if" scenario. Several other types of data were required for mileage adjustment. These data were collected from government agencies from 1990-2016 and are presented in Table 1. The other countryspecific modelling parameters such as speed, peak and off-peak share, share of urban, rural highway mileage, etc. were kept identical to the original scenario which were described in previous studies [5], [6]. In addition to these, total PC fleet size (TOT) which was a sum of petrol and diesel PCs was also applied as an indicator in modelling the fleet.

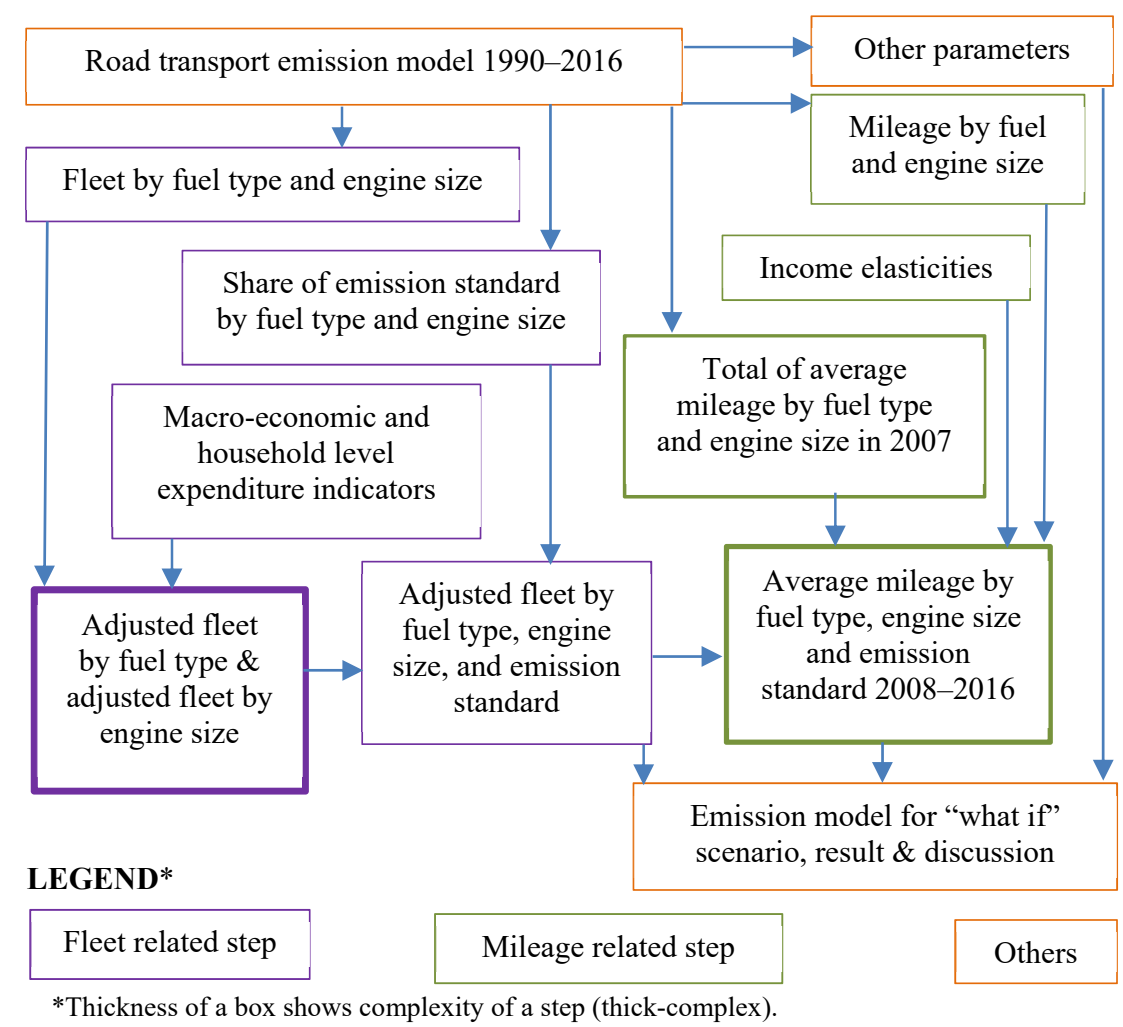

Figure 1: Analytical approach. 
Table 1: Data types with sources in this analysis.

\begin{tabular}{|c|c|c|c|c|}
\hline Data & Code & Unit & Source & Applied as/for* \\
\hline Gross National Product & GNP & $\begin{array}{c}2014 \text { market } \\
\text { prices in } € \\
\text { millions } \\
\end{array}$ & [7] & Obtained/M \\
\hline $\begin{array}{l}\text { Gross National Product } \\
\text { per ' } 000 \text { population }\end{array}$ & pGNP & $\begin{array}{l}2014 \text { market } \\
\text { prices in } €\end{array}$ & [7] & Derived/M \\
\hline $\begin{array}{c}\text { Population aged over } 15 \\
\text { years }\end{array}$ & POP & '000 & [7] & Obtained/M \\
\hline Gross Domestic Product & GDP & Current US\$ & [8] & Obtained/M \\
\hline Annual GDP growth & gGDP & Percentage $(\%)$ & [8] & Obtained/M \\
\hline $\begin{array}{c}\text { Employment to population } \\
\text { (age } 15+\text { ) ratio }\end{array}$ & EMP & Ratio & [7], [8] & Derived/M \\
\hline $\begin{array}{l}\text { Final consumption and } \\
\text { expenditure }\end{array}$ & $\mathrm{C} \& \mathrm{E}$ & $\begin{array}{l}\text { Percentage of the } \\
\text { GDP }(\%)\end{array}$ & [8] & Obtained/M \\
\hline $\begin{array}{l}\text { Household final } \\
\text { consumption and } \\
\text { expenditure }\end{array}$ & hC\&E & $\begin{array}{c}\text { Constant } 2010 \\
\text { US\$ }\end{array}$ & [8] & Obtained/M \\
\hline $\begin{array}{c}\text { Annual growth of } \\
\text { household final } \\
\text { consumption expenditure }\end{array}$ & gHCW & Percentage (\%) & [8] & Obtained/M \\
\hline $\begin{array}{c}\text { Average Vehicle } \\
\text { Registration Tax ** }\end{array}$ & VRT & $€$ & [9], [10] & Derived/M \\
\hline $\begin{array}{c}\text { Fuel price for petrol and } \\
\text { diesel }\end{array}$ & $\mathrm{P}$ & $€ /{ }^{\prime} 000$ litre & [4] & Obtained/A \\
\hline Average Motor Tax ** & MT & $€$ & {$[9],[10]$} & Derived/M \\
\hline $\begin{array}{c}\text { Income Elasticity of } \\
\text { Mileage }\end{array}$ & I & Numeric figure & [10], [11] & Obtained/A \\
\hline
\end{tabular}

\subsection{Fleet modelling}

The gasoline and diesel PC fleets in the COPERT model had a disaggregation of five engine sizes (as listed in Table 2), and seven emission standards (conventional \& EURO emission standard 1 to 6). In the "what if" scenario, the fleet modelling was conducted in a two-stage process. In the first stage, a shift in the fleet from petrol to diesel PC categories was modelled to calculate fleet size. A shift of the engine size was modelled in the second stage. In both stages, the last vehicle category $\left(\mathrm{n}^{\text {th }}\right)$ was not modelled, they $\left(F_{n^{t h}}\right)$ were estimated from the subtraction of the summed modelled fleets categories $\left(\sum_{0}^{n-1} F_{n}\right)$ from the total fleet $\left(F_{n}\right)$. This (n-1) modelling approach was considered to keep the total fleet size the same as the original scenario. The fleet size by fuel type was modelled in the first stage whereas the share (\%) of the fleet categories by fuel and engine size was modelled in the second stage. This was to facilitate calculating disaggregated fleet by fuel and engine size through multiplication after calculation of data of $\mathrm{n}^{\text {th }}$ fleet from both stages. Following this process, one fleet category was modelled in the first stage and two categories were modelled in the second stage. The 
Table 2: Average MT and VRT.

\begin{tabular}{|c|c|c|c|c|c|c|c|}
\hline \multirow{2}{*}{ Category } & \multirow{2}{*}{ Modelled } & \multicolumn{3}{|c|}{ MT $(€)$} & \multicolumn{3}{c|}{ VRT (\%) } \\
\cline { 3 - 8 } & & $\begin{array}{c}\text { Before } \\
2008\end{array}$ & After 2008 & $\mathrm{r}$ & $\begin{array}{c}\text { Before } \\
2008\end{array}$ & After 2008 & $\mathrm{r}$ \\
\hline Petrol <1.4* & Yes & 231.3. & 179.5. & -0.48 & 23.1. & 16.5. & -0.48 \\
\hline Petrol 1.4-2L** & Yes & 440.3. & 508.0. & -0.51 & 25.0. & 25.3. & -0.51 \\
\hline Petrol $>2 \mathrm{~L}$ & No & 975.0. & 1575.0. & -0.36 & 30.0. & 34.0. & -0.36 \\
\hline Diesel $<2^{* * *}$ & Yes & 320.9. & 169.4. & 0.59 & 23.9. & 16.3. & 0.59 \\
\hline Diesel $>2$ & No & 975.0. & 1325.0. & 0.59 & 30.0. & 32.0. & 0.59 \\
\hline
\end{tabular}

${ }^{*} \mathrm{r}:(\mathrm{POP}=-0.13, \mathrm{TOT}=-0.57, \mathrm{pGNP}=0.34) ;{ }^{* *} \mathrm{r}:(\mathrm{POP}=0.07, \mathrm{TOT}=0.51, \mathrm{pGNP}=-0.42) ; * * * \mathrm{r}:(\mathrm{POP}=-0.86, \mathrm{TOT}=$ $-0.42, \mathrm{pGNP}=-0.33)$.

share of emission standard by fuel type and engine size was considered unchanged on an assumption that the purchasing time of the vehicle would not be interrupted. This share was applied to the disaggregated fleet by fuel and engine size of the two-stage process to derive fleet disaggregated by fuel, engine size and emission standard. The determination of emission standard and vehicle purchase year was previously modelled [5].

The fleet modelling in two stages was carried out through a regression analysis. The uninfluenced fleet sizes by fuel or by fuel and engine size before the reform were regressed against suitable indicators from 1990-2007, and the developed models were applied for the prediction of fleet categories from 2008 to 2016 without the influence of the diesel incentive. Regression was previously applied in fleet modelling [5], [6], [12] in the form of Multiple Linear Regression (MLR) shown in eqn (1)

$$
F=C_{0}+A_{1} * X_{1}+A_{2} * X_{2}+\cdots .+A_{n} * X_{n}+\epsilon,
$$

where, $F=$ Fleet size in a category; $C_{0}=$ Intercept; $X_{n}=$ nth predictor variable; $A_{n}=$ regression coefficient for the nth predictor variable; $\epsilon=$ Error.

\subsection{Mileage}

The original average mileage $(M)$ by emission standard (e), engine size (z) and fuel type (f) were expressed as $M_{f, z, e}$ and these notation keys for disaggregation of mileage have been applied to eqns (2)-(6). The $M_{f, z, e}$ was available for 1990-2016 in the COPERT database. In the "what if" scenario, mileage adjustment was carried out in a three-step procedure to match the same level of disaggregation of mileage from 2008-2016. The mileage was predicted at fuel and engine size level first and in the next step, the mileage was disaggregated by emission standard, fuel and engine size. Finally, the estimated mileage was adjusted to the total mileage.

To predict the mileage by fuel and engine size in future years $\left(\overline{M_{f, z}}\right)$ to reflect the fleet change impact and vehicle use decisions in the "what if" scenario, unaffected mileage $\left(M_{f, z}\right)$ of 2007 was considered as a function of income elasticities $\left(I_{z}\right)$ of mileage by engine size, and the fuel price $\left(P_{f}\right)$ for future years as shown in eqn (2) and in detail in eqn (3) [13]

$$
\overline{M_{f, z}}=f\left(M_{f, z}, I_{z}\right) \text {. }
$$


The total average mileage of all emission standards at the level of fuel and engine size $\left(\overline{M_{f, z}}\right)$ for 2008-2016 under the "what if" scenario was derived from eqn (3):

$$
\overline{M_{f, z,(t+1)}}=\left(1+I_{z} *\left(1-\frac{P_{f,(t+1)}}{P_{f, t}}\right)\right) * M_{f, z, t} .
$$

Predicted total average mileage by fuel and engine was distributed to the emission standard level and predicted total mileage by fuel, emission and engine size was calculated using the fleet size from the "what if" scenario, i.e. eqn (4).

$$
\overline{T_{f, z, e}}=\hat{F}_{f, z, e} * M_{f, z, e} * \frac{\sum_{E=0}^{E=n} M_{f, z, e}}{\overline{M_{f, z}}},
$$

Finally, average mileage by fuel, engine and emission standard $\left(\dot{M}_{f, z, e}\right)$ under the "what if" scenario that is required for COPERT modelling, was derived following eqn (5). In this equation, a yearly adjustment factor (n) was applied. The factor is a ratio between the total original mileage in a year and the predicted total mileage in a year across all vehicle categories in eqn (6). This equation ensured that the total mileage produced by this step, remained the same as the original scenario

whereas,

$$
\dot{M}_{f, z, e}=n * \overline{T_{f, z, e}} * \frac{1}{\hat{F}_{f, z, e}}
$$

$$
n=\frac{\sum T_{f, z, e}}{\overline{\sum T_{f, z, e}}} .
$$

\section{RESULT}

\subsection{Fleet}

From Table 1, hC\&E and GDP indicators were selected by a forward selection procedure in the regression model to explain the time series variation of the petrol fleet from 1990-2007, on the basis of Pearson correlation coefficients. The maximum Variance Inflation Factor (VIF) was $<2.2$, the adjusted coefficient of determination and its validation both $\left(\mathrm{R}^{2}=0.99\right)$ were acceptable. The developed model for the petrol fleet size in the "what if" scenario was shown in eqn (7). The model was applied to the indicators data from 2008-2016 to estimate petrol PC size. The diesel PC fleet was calculated from the total PC and shown in Fig. 2. The shifted vehicles from diesel PC were 22,457 in 2008 which gradually increased to 542,140 in 2016

$$
\hat{F}_{p}=-17070000+723800 * \log (h C \& E)+0.0000008756 * G D P+\epsilon_{p},
$$

where, $F_{p}=$ Fleet size of the petrol PC; $\in=$ Error.

In the second stage, the share of engine size by fuel for PC was modelled (Fig. 3). Three fleet types by engine for petrol and diesel fuel categories were modelled. The fleet size for the remaining categories were estimated using (n-1) approach. Fleet size data from 19902007 was modelled in the first stage original indicator values were applied for prediction in 


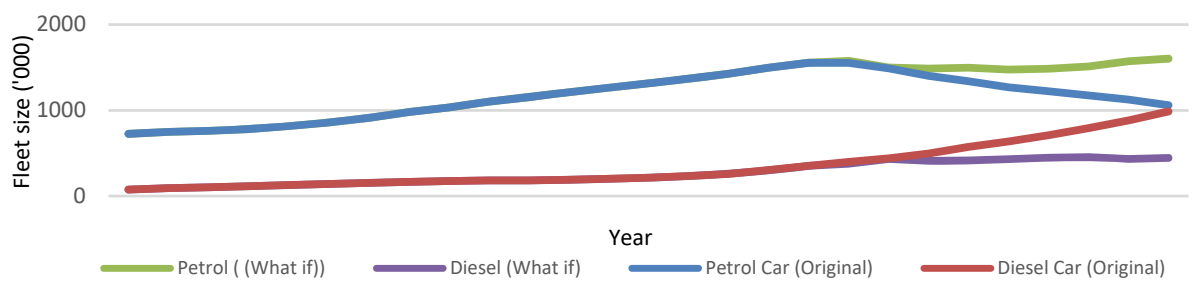

Figure 2: Fleet size 1990 to 2016: original and "what-if" scenarios.

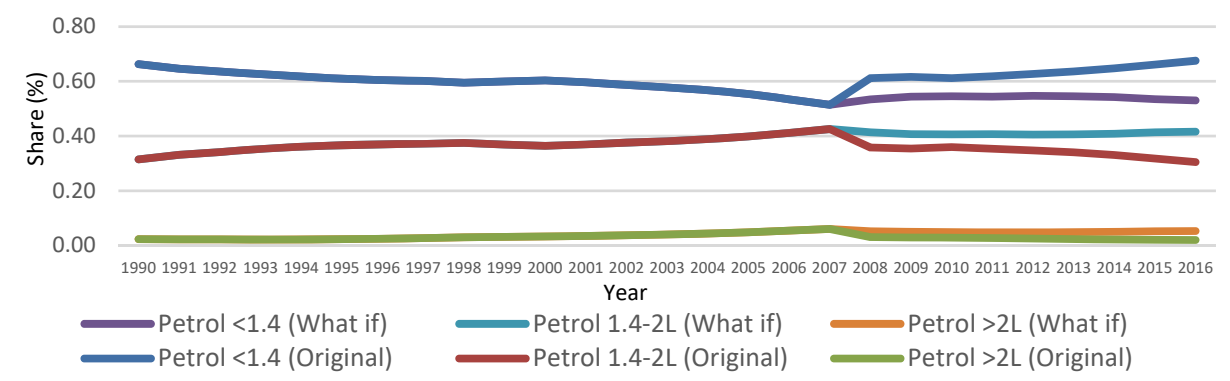

(a)

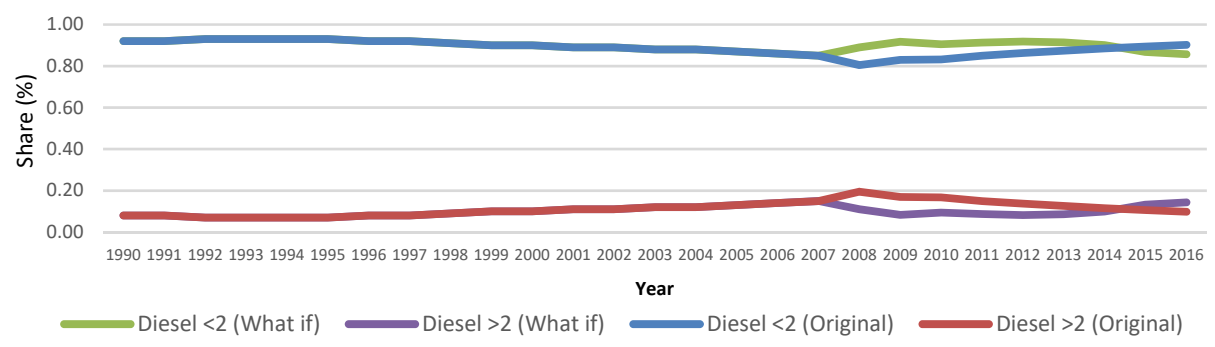

(b)

Figure 3: Share between engine sizes. (a) Petrol; (b) Diesel.

the period 2008-2016. Whereas, fleet shares from 1990-2016 were modelled in the second stage, using the original indicator values and in prediction the share of fleets for "what if" scenario (see Table 2), the MT and VRT indicators were kept constant for the post-2007 years. Along with MT and VRT, three additional indicators were assessed and their Pearson correlation coefficient, $\mathrm{r}$ was given in Table 2.

The result models for $F_{p<1.4}^{\prime}, F_{p 1.4-2}^{\prime}$ and $F_{D<2}^{\prime}$ fleets in the "what if" scenario are presented in eqns (8)-(10). The maximum VIF, adjusted $\mathrm{R}^{2}$ and the validation $\mathrm{R}^{2}$ for the models were $1.17,1.17$ and 6.5 , and $0.90,0.93$ and 0.88 , and $0.95,0.92$ and 0.95 respectively

$$
\begin{gathered}
\hat{F}_{p<1.4}=1.022-0.0012440000 * M T-0.0000001271 * \text { TOT }+\epsilon_{<1.4}, \\
\hat{F}_{p 1.4-2}=0.5888000000-0.0007121 * M T+0.0000000880 * T O T+\epsilon_{p 1.4-2}, \\
\hat{F}_{D<2}=1.763-0.185 * \log (G N P)+0.0007041 * M T 0.000000273 * \text { TOT }+\in_{D<2} .
\end{gathered}
$$


The $\hat{F}_{p>2}$ and the $F_{D>2}$ for Petrol $>2 \mathrm{~L}$ and Diesel $>2 \mathrm{~L}$ in "what if" were calculated from these eqns $\left(\hat{F}_{p>2}=1-\sum_{p<1.4}^{p 1.4-2} \hat{F}_{p} ; \hat{F}_{D>2}=1-\hat{F}_{D<2}\right)$ and the results were presented in Fig. 3(a) and $3(\mathrm{~b})$.

In the "what if" scenario of the petrol PC in Fig. 3(a), the share of smallest engine size was reduced by a rise in the other two engine sizes. Whereas, the opposite phenomenon was noticed for diesel vehicles (Fig. 3(b)). However, the gap closed in the middle of 2015 and people were predicted to be interested in buying higher engine sized diesel PCs in 2016, compared to the historical trend. The share of fleets by fuel in Fig. 3(a) and (b) was multiplied with fleet size by fuel in Fig. 2 and the original share of fleet emission standard to estimate the most disaggregated fleet (Fig. 4).

\subsection{Mileage}

The income elasticity of mileage -0.3 for smaller engine size categories [11] and a zero value for the higher engine sized PCs (assuming no impact of fuel price on vehicle use as per [10] were applied in conjunction with the fuel price on the original mileage of 2007. After applying eqns (3)-(6), the average mileage per vehicle was derived and shown in Figs 5 and

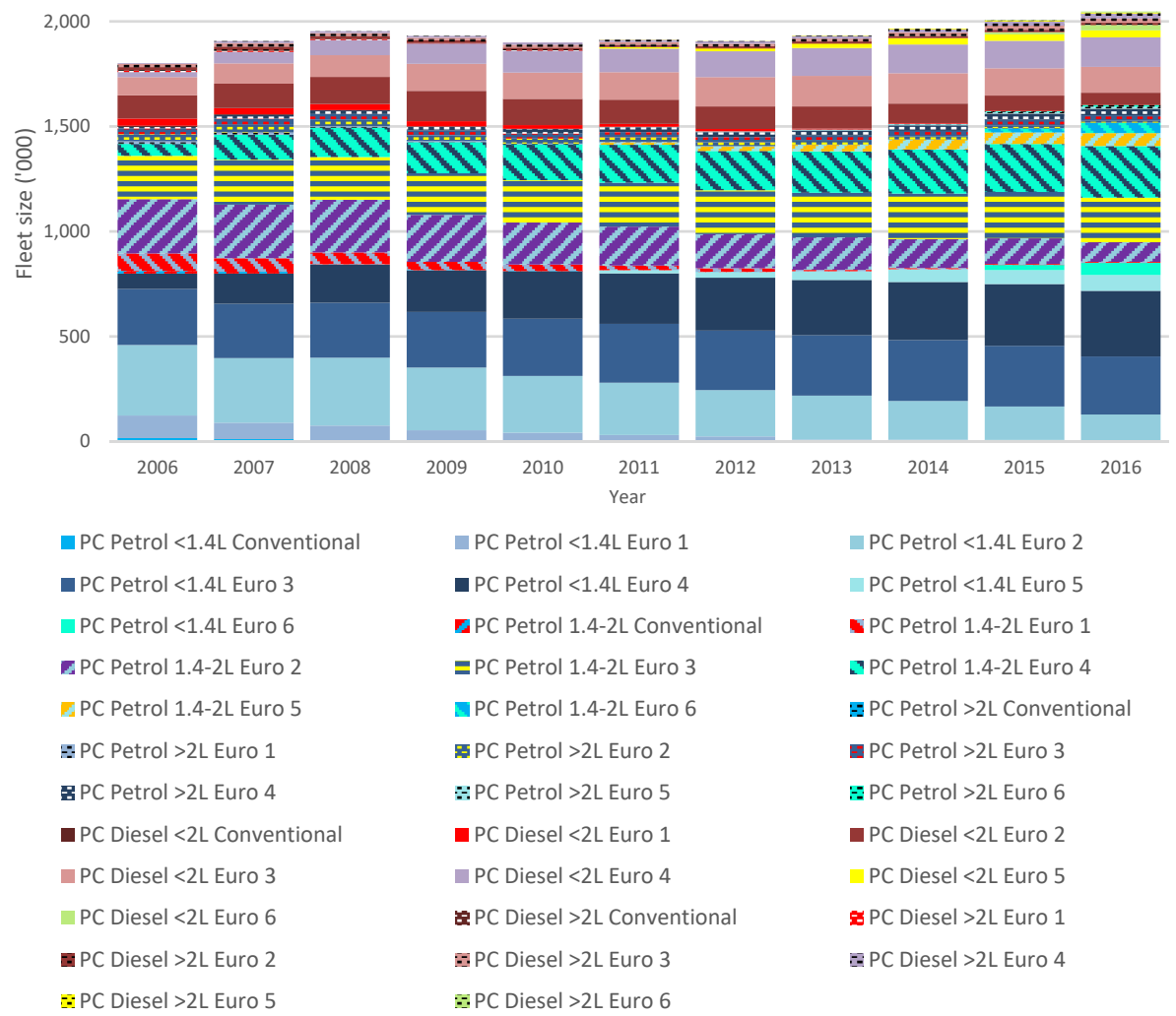

Figure 4: Disaggregate fleet size in "what if" scenario. 
6. The value for " $n$ " in eqn (6) was found in the range $0.77-1.09$ (average was 0.91 with a standard deviation of 0.11 ).

From the mileage adjustment process, an increase in average mileage per vehicle category is noticeable for Figs 5 and 6 . As the price of the fuel started to decline in 2012, the mileage increased. In the last two years, the mileage for all vehicles increased, especially for the diesel vehicles in Fig. 6, reflecting that thee price decline rate of diesel fuel price is higher than that of the petrol price. In addition, the increase of mileage was also higher for PC engine size $>2 \mathrm{~L}$ as they were modelled as inelastic to fuel price.

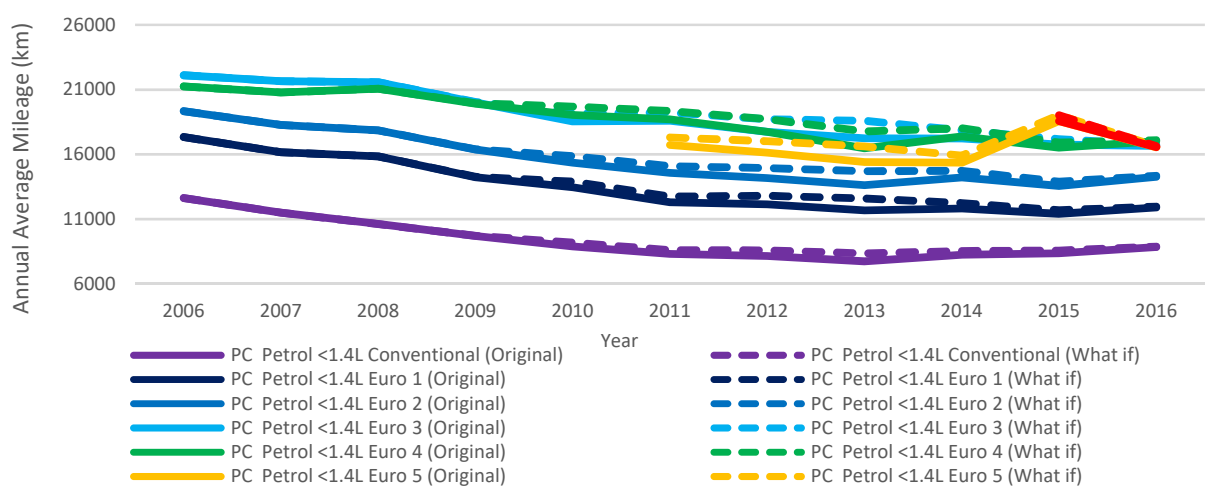

(a)

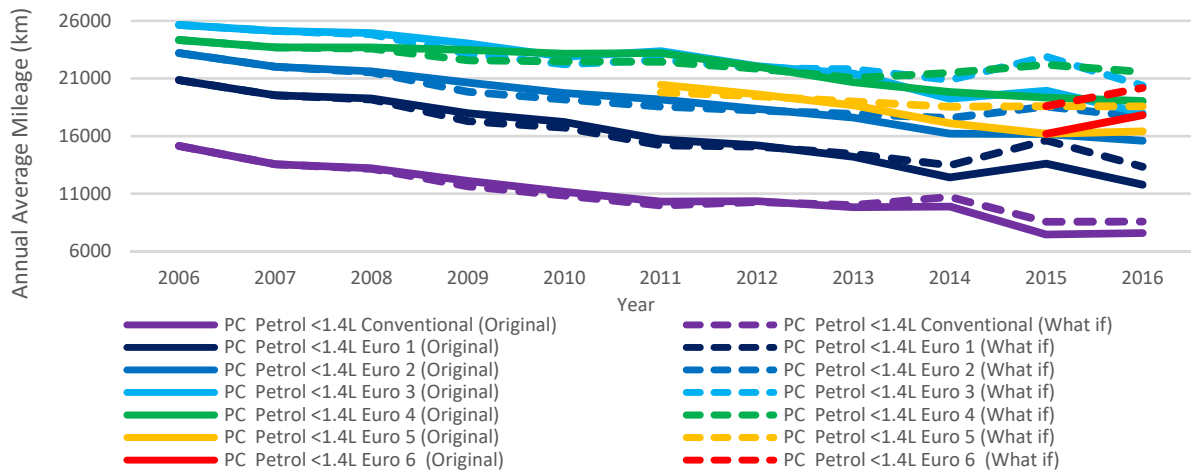

(b)

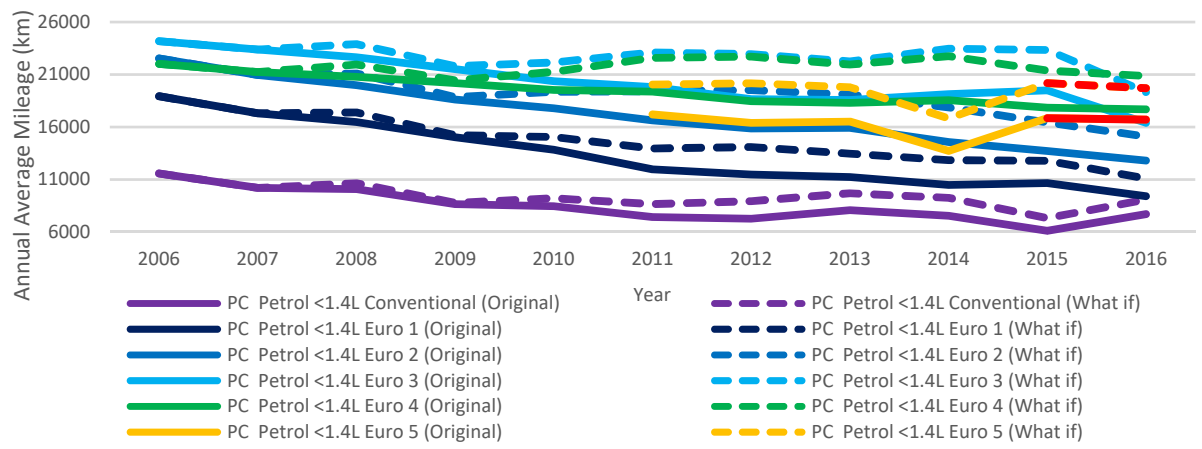

(c)

Figure 5: Annual average mileage for petrol powered PC. (a) $<1.4 \mathrm{~L}$; (b) $1.4-2 \mathrm{~L}$; (c) $>2 \mathrm{~L}$. 


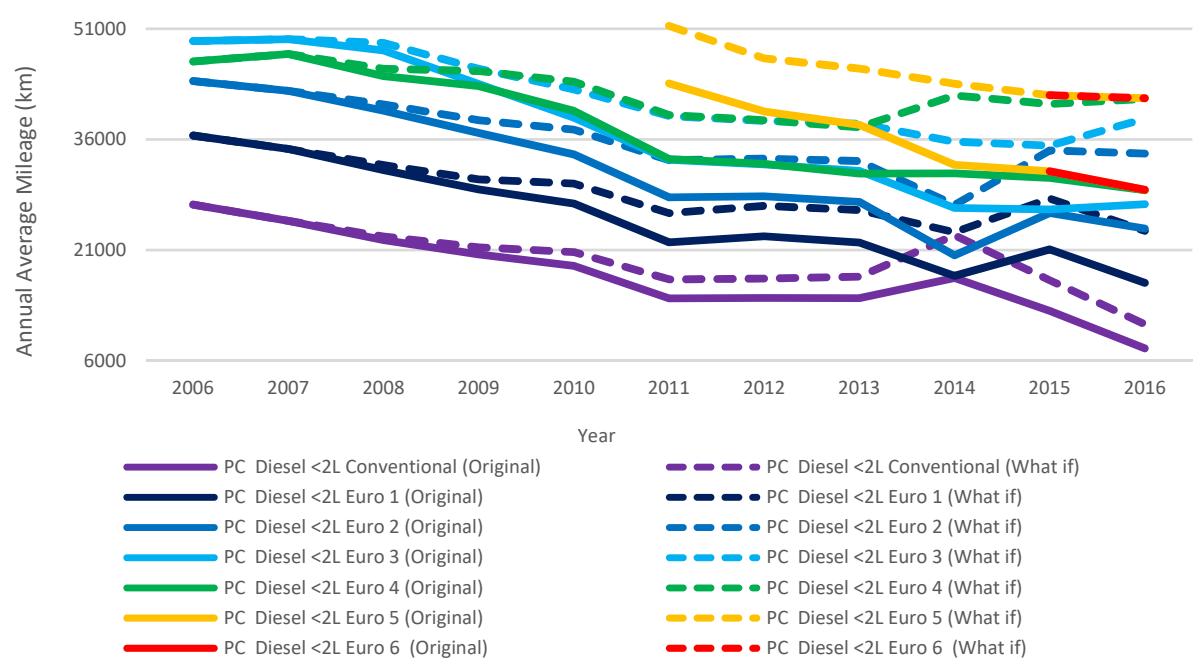

(a)

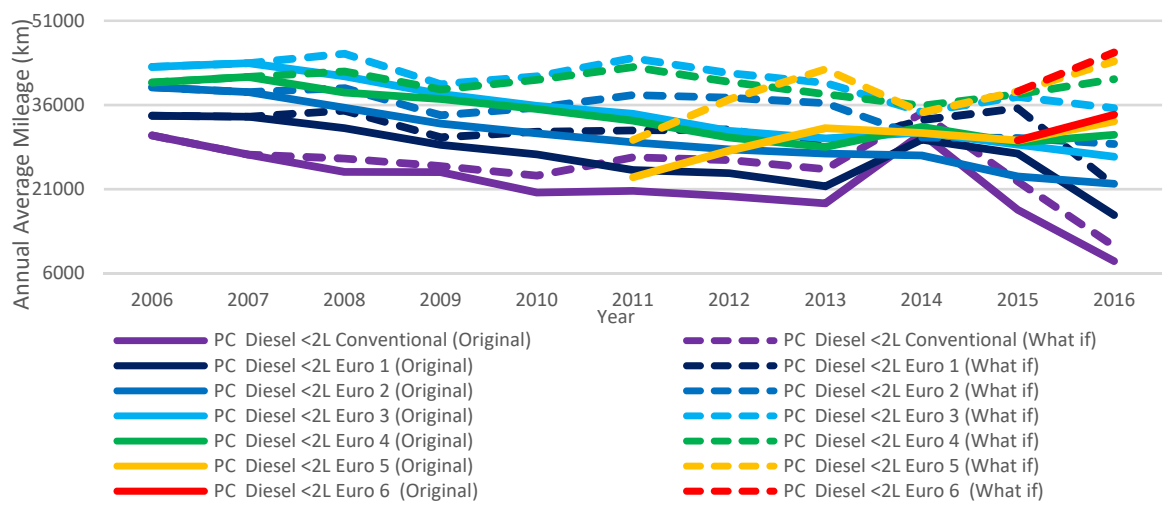

(b)

Figure 6: Annual average mileage for diesel powered PC. (a) $<2 \mathrm{~L}$; (b) $>2 \mathrm{~L}$.

\subsection{Total emission}

When predicted emission figures were compared against the original scenario, the following difference was found in Fig. 7. The result shows that the difference would be approximately a $5.4 \%$ increase of $\mathrm{CO}_{2}$ and $6.4 \%$ for $\mathrm{PM}_{2.5}$ in 2016 without the implementation of the 2008 diesel incentives. $\mathrm{NH}_{3}, \mathrm{CO}, \mathrm{NMVOC}$ and $\mathrm{CH}_{4}$ would also have been increased by $50.9 \%$ to $61.9 \%$. The nitrogen-based emissions, however, would have reduced by $22.8 \%$ for $\mathrm{NO}_{\mathrm{x}}$ and $19.9 \%$ for $\mathrm{N}_{2} \mathrm{O}$.

\section{DISCUSSION AND CONCLUSION}

The current policy favours diesel passenger cars in Ireland and encourages an increase in the purchase of smaller engine vehicles. Their combined effect resulted in lower levels of 


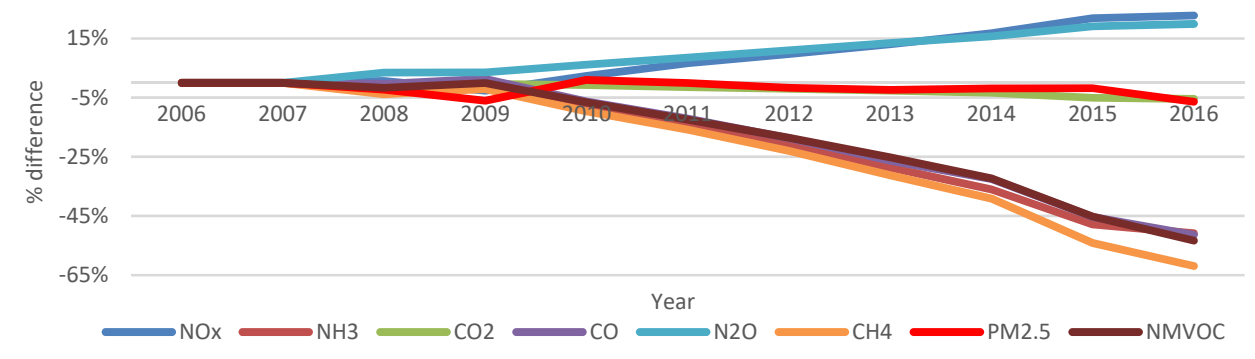

Figure 7: Difference in emissions in "what if" and original scenario.

emissions for some GHGs and air pollutants since 2008, however, the $\mathrm{NO}_{\mathrm{x}}$ and the $\mathrm{N}_{2} \mathrm{O}$ emissions were increased in the process. If this diesel incentive was not enacted, the results of this "what if" scenario showed that all pollutants would have increased with the exception of $\mathrm{NO}_{\mathrm{x}}$ and $\mathrm{N}_{2} \mathrm{O}$, which would have reduced. Moderate increases in $\mathrm{CO}_{2}$ and $\mathrm{PM}_{2.5}$ would have occurred in the absence of the diesel incentive due to lack of a push to purchase smaller engine vehicles, and due to the more $\mathrm{CO}_{2}$ efficient nature of diesel engines. In the case of $\mathrm{PM}_{2.5}$, while diesel vehicles are known to produce more of these emissions than petrol equivalents, again the lack of an incentive for smaller engines together with a smaller difference between $\mathrm{PM}_{2.5}$ emissions in higher EURO classes, acted to result in a worse situation for $\mathrm{PM}_{2.5}$ in the "what-if" scenario. Purchases of larger engine petrol vehicles prevailed in the fleet in the "what if" scenario, increasing the emission of $\mathrm{PM}_{2.5}$ relative to smaller engine diesels in the current scenario.

As both the $\mathrm{NO}_{\mathrm{x}}$ and $\mathrm{N}_{2} \mathrm{O}$ showed a significant difference while comparing results between scenarios, the cause of this is worth further discussion. The most impacting fleet categories for $\mathrm{NO}_{\mathrm{x}}$ and $\mathrm{N}_{2} \mathrm{O}$ emission were identified as diesel $<1.4 \mathrm{~L}$. Thus, it is noticeable that a change in fleet size in this technology would likely have the most impact on the emission scenario. Using this knowledge of a fleet category shift, a framework tool could be developed to control the future fleet composition.

An impact on emission reduction caused by a switch of one unit of a fleet category to others may be calculated from these two scenarios. Priority emissions and pollutants can be determined through national emission reduction targets or based on their weighted negative impacts on health and environment. Two emission types with the most priorities and each from positive and negative difference from the scenario comparison analysis can be applied to monitor the level of shifts between technologies. When satisfactory levels of emissions can be determined, the fleet composition is considered as an optimal fleet composition for a year. Optimal fleet composition in every historic year can be applied with macro-economic data to project optimum future fleet composition to indicate the changes required in the current taxation policy.

The results of this investigation highlight that incentivising one fuel type over another or more broadly one vehicle category over another, is a complex process with potentially positive and negative outcomes. The results highlight that either incentivising diesel or petrol each has negative consequences. Policy should instead incentivise a fleet composition which optimises the total emission. Further research is required to develop such an optimisation tool which is linked to reasonable and regular policy adjustments. 


\section{ACKNOWLEDGEMENT}

This work was supported by the EPA Research Programme: Project 2017-CCRP-FS.34.

\section{REFERENCES}

[1] Giblin, S. \& McNabola, A., Modelling the impacts of a carbon emission-differentiated vehicle tax system on $\mathrm{CO}_{2}$ emissions intensity from new vehicles in Ireland. Energy Policy, 37, pp. 1404-1411, 2009.

[2] Degraeuwe, B. et al., Impact of passenger car $\mathrm{NO}_{\mathrm{x}}$ emissions on urban $\mathrm{NO}_{2}$ pollution - Scenario analysis for 8 European cities. Atmospheric Environment, 171, pp. 330337, 2017.

[3] Leinert, S., Daly, H.E., Hyde, B. \& Ó'Gallachóir, B.P., Co-benefits? Not always: quantifying the negative effect of a $\mathrm{CO}_{2}$-reducing car taxation policy on $\mathrm{NO}_{\mathrm{x}}$ emissions. Energy Policy, 63, pp. 1151-1159, 2013.

[4] EPA, personal communication, Emissions Inventory Team, Environmental Protection Agency (EPA), 14 Feb. 2018.

[5] Alam, M.S., Duffy, P., Hyde, B. \& McNabola, A., Improvement in the estimation and back-extrapolation of $\mathrm{CO}_{2}$ emissions from the Irish road transport sector using a bottom-up data modelling approach. Transportation Research Part D: Transport and Environment, 56, pp. 18-32, 2017.

[6] Alam, M.S., Hyde, B., Duffy, P. \& McNabola, A., Assessment of pathways to reduce $\mathrm{CO}_{2}$ emissions from passenger car fleets: case study in Ireland. Applied Energy, 189, pp. 283-300, 2017.

[7] CSO, Central Statistical Office Database, Online. www.cso.ie/en/databases. Accessed on: 14 Feb. 2018.

[8] WB - World Bank, World Development Indicators (Ireland), 2016, Online. http://data.worldbank.org/country/ireland. Accessed on: 14 Feb. 2018.

[9] DEHLG, Rates of duty on Motor vehicles, 2008, Online. https://www.motortax.ie/OMT/pdf/motortax_rates_2009_en.pdf. Accessed on: 14 Feb. 2018.

[10] Hennessy, H. \& Tol, R.S.J., The impact of tax reform on new car purchases in Ireland. Energy Policy, 39, pp. 7059-7067, 2009.

[11] Daly H.E. \& Ó'Gallachóir, B.P., Modelling future private car energy demand in Ireland. Energy Policy, 39(12), pp. 7815-7824, 2011.

[12] Hao, H., Liu, Z., Zhao, F., Li, W. \& Hang, W., Scenario analysis of energy consumption and greenhouse gas emissions from China's passenger vehicles. Energy, 91, pp. 151-159, 2015.

[13] Hayashi, Y., Kato, H., \& Teodoro, R.V.R., A model system for the assessment of the effects of car and fuel green taxes on $\mathrm{CO}_{2}$ emission. Transportation Research Part D, 6, pp. 123-139, 2001. 